\title{
Meningkatkan Hasil Belajar Siswa Melalui Model Cooperative Learning Dengan Media Proyeksi LCD Pada Keterampilan Mendengarkan
}

\author{
R Wiwik Sulistiyani \\ SDN Karangtengah 4 Ngawi \\ Wiwiksulis12@gmail.com
}

\begin{abstract}
Abstrak
Setelah diadakan observasi di kelas V SDN Karangtengah 4 ditemukan permasalahan hasil ulangan formatif mata pelajaran Bahasa Indonesia pada keterampilan mendengarkan masih ada $50 \%$ siswa yang nilainya di bawah KKM yaitu 70. Tujuan penelitian ini adalah untuk mendeskripsikan dan menganalisis cara meningkatkan hasil belajar kelas V SDN Karangtengah 4 pada keterampilan mendengarkan melalui model cooperative learning dengan media proyeksi LCD. Penelitian ini dilaksanakan di kelas V SDN Karangtengah 4 Kecamatan Ngawi Kabupaten Ngawi. Dengan sasaran mata pelajaran Bahasa Indonesia. Rencana perbaikan pembelajaran ini menggunakan PTK. Hasil dari penelitian ini adalah meningkatnya hasil belajar siswa kelas V SDN Karangtengah 4 setelah diterapkan model cooperative learning dan media proyeksi LCD dalam pembelajaran, dari pra siklus yang mendapat $50 \%$ kemudian siklus $173 \%$ lalu siklus $2100 \%$. Kesimpulan dari penelitian ini adalah penerapan model cooperative learning dan media proyeksi LCD dapat meningkatkan hasil belajar siswa kelas V SDN Karangtengah 4 Kecamatan Ngawi pada keterampilan mendengarkan.
\end{abstract}

Kata Kunci: Hasil belajar, Model Cooperative Learning, Media Proyeksi LCD, Keterampilan Mendengarkan

\section{PENDAHULUAN}

Bahasa adalah alat komunikasi sosial yang sangat penting bagi manusia. Aktivitasa manusia sebagai anggota masyarakat tergantung pada kemampuan penggunaan bahasa setempat. Bahasa merupakan tanda yang jelas dari kepribadian seseorang, karena dari bahasa yang digunakan kita dapat memahami motif, latar belakang pendidikan, keinginan, pergaulan, dan adat istiadat seseorang. Samsuri (1991: 4). Manusia memerlukan bahasa dalam segala kegiatan baik dalam bidang akademis, pemerintahan, sosial, budaya, seni, politik, dan dalam kegiatan hidup praktis. Melihat pentingnya bahasa bagi manusia dalam kehidupan, maka pendidikan bahasa perlu dilakukan sejak dini baik keterampilan berbicara, keterampilan membaca, keterampilan menulis, maupun keterampilan menyimak (mendengar). Berdasarkan hasil observasi serta wawancara dengan guru kelas V SDN Karangtengah 4, Kecamatan Ngawi, Kabupaten Ngawi, diperoleh penjelasan bahwa hasil ulangan formatif mata pelajaran Bahasa Indonesia pada keterampilan mendengarkan masih ada $50 \%$ siswa yang mendapatkan nilai di bawah KKM yang telah ditentukan yaitu 70. Selain itu hasil ofservasi kami menemukan bahwa siswa didalam mengikuti proses belajar Bahasa Indonesia pada keterampilan mendengarkan terlihat tidak bersemangat, ini dapat terlihat dari tidak adanya siswa yang bertanya namun apabila diberi pertanyaan hanya 5\% siswa saja yang bisa menjawab.

Rendahnya nilai Bahasa Indonesia dari KKM yang telah ditentukan dan kurangnya daya tarik siswa kelas $\mathrm{V}$ dalam 
belajar Bahasa Indonesia khususnya keterampilan mendengarkan , hal ini disebabakan karena guru dalam mengajar masih menggunakan metode ceramah dan hanya menggunakan media buku teks saja pada saat menyampaikan materi pelajaran. Sehingga siswa kurang tertarik dan merasa kesulitan didalam menerima pembelajaran. Untuk mengatasi ketidak tertarikan siswa akan mata pelajaran Bahasa Indonesia pada keterampilan mendengarkan ini maka diadakan inovasi pembelajaran dalam mengubah strategi pembelajaran, supaya siswa lebih tertarik dan lebih mudah memahami pembelajaran Bahasa Indonesia pada keterampilan mendengarkan. Berdasarkan hasil penilaian dan ofservasi tersebut di atas, maka diperlukan suatu perbaikan dalam proses pembelajaran di kelas V SDN Karangtengah 4, Kecamatan Ngawi, Kabupaten Ngawi. Perbaikan pembelajaran tersebut dengan cara menerapkan pembelajaran melalui model cooperative learning dengan media proyeksi LCD yang dapat mempermudah siswa dalam memahami keterampilan mendengarkan pada mata pelajaran Bahasa Indonesia.

Pendekatan cooperative learning adalah pembelajaran yang menggunakan kelompok kecil sehingga siswa dapat bekerja sama untuk memaksimalkan kegiatan belajarnya sendiri dan juga anggota yang lain. Sedangkan media proyeksi LCD adalah media visual yang dapat diproyeksikan, sehingga dengan alat ini diharapkan siswa lebih tertarik dalam proses pembelajaran. Berdasarkan latar belakang masalah di atas maka dapat dijadikan dasar untuk mengadakan suatu penelitian tindakan yang berjudul "Meningkatkan Hasil Belajar Siswa Kelas V SDN Karangtengah 4 Kecamatan Ngawi Pada Keterampilan Mendengarkan Melalui Model Cooperative Learning Dengan Media Proyeksi LCD”.
Di dalam perkembangan dan pertumbuhan siswa sekolah dasar dipengaruhi oleh faktor lingkungan sekitarnya. Kondisi lingkungan yang berbeda-beda inilah yang menyebabakan setiap siswa mempunyai karakteristik yang berbeda antara individu yang satu dengan individu yang lainnya.Karakteristik perkembangan siswa sekolah dasar terdiri dari: 1) Perkembangan fisik siswa, 2) perkembangan motorik siswa, 3) perkembangan emosional siswa, 4) perkembangan sosial siswa, 5) perkembangan intelektual siswa, 6) perkembangan bahasa siswa, 7) perkembangan moral siswa, 8) perkembangan spiritual siswa. Perkembanan fisik siswa sekolah dasar dipengaruhi oleh pengaruh keluarga/keturunan; siswa yang kedua orang orang tua atau salah satunya mempunyai badan tinggi besar maka anaknya akan mempunyai tubuh yang lebih besar dari teman seusianya begitu juga sebaliknya. 2) gizi, siswa yang mempunyai keluarga yang cukup gizinya dan baik perawatannya maka anaknya akan memiliki badan yang tinggi besar dan sehat sebaliknya anak yang mengalami kekurangan gizi akan mengalami pertumbuhan yang lambat. 3) tingkat sosial ekonomi, siswa yang mempunyai tingkat sosial ekonomi yang lebih tinggi biasanya akan lebih terpenuhi kebutuhan fisiknya, 4) faktor emosional, siswa yang sering mengalami gangguan emosional akan menyebabkan terbentuknya steroid adrenal yang berlebihan, yang dapat menyebabkan berkurangnya pembentukaan hormon pertumbuhan di kelenjar pituitary. Siswa yang mengalami tekanan atau tidak nyaman di lingkungannya akan menyebabkan siswa menjadi pendiam, sulit bergaul, ragu-ragu dalam bertindak, pemurung sehingga terhambat pertumbuhan fisiknya. 5) Jenis kelamin, perbedaan jenis kelamin pada siswa sekolah dasar dalam pertmbuhan fisiknya hampir tidak ada perbedaan yang menonjol 
sampai mulai perubahan pubertas, sekitar usia 11-12 tahun, anak perempuan lebih cepat tinggi dan berat daripada anak laki-laki. 6) kesehatan, siswa yang sehat biasanya memiliki badan yang berat dan tinggi dari pada anak yang sering sakit-sakitan, siswa yang sehat dan segar penampilannya aktif bergerak seakan tidak pernah lelah. 7) suku bangsa/ras, kondisi fisik siswa berbeda-beda antara suku, ras atau bangsa tertentu, ini dapat dilihat dari warna kulit, rambut,bentuk badannya (IG.A.K.Wardani,dkk, 2009: 4.34.4).

Hasil belajar merupakan kulminasi dari suatu proses yang telah dilakukan dalam belajar. Kulminasi akan selalu diiringi dengan kegiatan tindak lanjut. Hasil belajar harus menunjukkan suatu perubahan tingkah laku dari siswa yang sifatnya menetap, fungsional, positif, dan disadari. Perubahan tingkah laku dari hasil belajar harus bersifat komprehensif atau menyeluruh bukan hanya pada satu aspek saja. Aspek keseluruhan perilau dari tujuan pembelajaran menurut Benyamin Bloom (1956) yang dapat menunjukkan gambaran haasil belajar, mencakup tiga aspek yaitu kognitif, afektif, dan psikomotorik. Menurut Romizoswki (1982) menyebutkan dalam skema kemampuan yang dapat menunjukkan hasil belajar yaitu: 1) keterampilan kognitif berkaitan dengan kemampuan membuat keputusan, memecahkan masalah, dan berpikir logis; 2) keterampilan psikomotor berkaitan dengan kemampuan tindakan fisik dan kegiatan perseptual; 3) keterampilan reaktif berkaitan dengan sikap, kebijaksanaan, perasaan, dan self control; 4) keterampilan interaktif berkaitan dengan kemampuan sosial dan kepemimpinan. (Sri Anitah W, dkk, 2009: 2.19).

Keterampilan mendengarkan adalah salah satu dari ruang lingkup dari standar kompetensi mata pelajaran Bahasa Indonesia di SD selain berbicara, membaca, dan menulis. Didalam kurikulum 2004 menyimak disebut dengan istilah mendengarkan. Mendengarkan atau menyimak dibagi menjadi dua yaitu: 1)menyimak lisan. Menurut Kamidjan (201:4) menyimak atau mendengarkan adalah suatu proses mendengarkan lambang-lambang bahasa lisan dengan sungguh-sungguh penuh perhatian, pemahaman, apresiatif yang dapat disertai dengan pemahaman makna komunikasi yang disampaikan secara non vebal. Didalam menyimak lisan harus memperhatikan aspek segmental yang berupa kata-kata dalam ucapan, selain itu harus juga memperhatikan aspek kinestik dan suprasegmental, yakni (a) tekanan atau keras lembutnya suara, (b) jeda atau panjang pendekya suara, (c) nada atau tinggi rendahnya suara, (d) intonasi atau naik turunnya suara, dan (e) ritme atau irama dalam suara (Sabarti, A. 1922: 147) 2)menyimak tulis terwujud dalam kegiatan menyimak atau mendengarkan bacaan. (Solchan T.W., dkk, 2011:10.9). Model pembelajaran merupakan bentuk pembelajaran yang tergambar dari awal sampai akhir yang disajikan secara khas oleh guru. Dengan kata lain model pembelajaran merupakan bungkus atau bingkai dari penerapan suatu pendekatan, metode, dan teknik pendekatan.

\section{METODE}

Subjek penelitian berbaikan pembelajaran ini adalah siswa kelas V SDN Karangtengah 4 Kecamatan Ngawi Kabupaten Ngawi Tahun Pelajaran 2017/2018 dengan jumlah siswa 22 orang terdiri dari 11 siswa lakilaki dan 11 siswa perempuan. Mata pelajaran yang menjadi sasaran dalam proses pembelajaran adalah mata pelajaran Bahasa Indonesia untuk kelas V, khususnya pokok bahasan keterampilan mendengarkan, dengan fokus perbaikan pembelajaran untuk : 1) Meningkatkan hasil belajar siswa pada keterampilan mendengarkan melalui pendekatan cooperative learning dengan 
media proyeksi LCD, 2) Memberikan pertanyaan dengan jelas kepada siswa agar siswa lebih mudah memahami materi pembelajaran. Tempat penelitian ini dilaksanakan di kelas V SDN Karangtengah 4 Kecamatan Ngawi Kabupaten Ngawi. Penelitian ini dilaksanakan di kelas V SDN Karangtengah 4 Kecamatan Ngawi Kabupaten Ngawi, dilaksanakan pada bulan Maret 2018. Terdiri dari 3 siklus dan setiap siklus dilaksanakan selama 1 kali pertemuan $(1$ x 35 menit). Prosedur pelaksanaan penelitian diawali dengan timbulnya masalah yang sudah teridentifikasi saat observasi awal, kemudian dilanjutkan dengan membuat rencana perbaikan pembelajaran. Rencana perbaikan pembelajaran untuk mata pelajaran Bahasa Indonesia kelas $\mathrm{V}$ SDN Karangtengah 4 Kecamatan Ngawi Kabupaten Ngawi Tahun pelajaran 2017/2018 dengan menggunakan penelitian tindakan kelas (PTK). PTK adalah proses penelitian yang sistematis dan terencana melalui tidakan perbaikan pembelajaran yang dilakukan oleh guru di kelasnya sendiri. Secara garis besar terdapat empat tahapan yang akan dilaksanakan pada penelitian tindakan kelas, yaitu: 1) perencanaan (planning), 2) pelaksanaann (acting), 3) pengamatan (observasi), 4) refleksi (reflecting).

Analisis data digunakan untuk mengetahui keefektifan suatu metode dalam kegiatan pembelajaran. Pada penelitian ini menggunakan teknik analisis deskriptif kualitatif, yaitu suatu metode penelitian yang bersifat menggambarkan kenyataan atau fakta yang sesuai dengan data yang diperoleh dengan tujuan mengetahui hasil belajar yang dicapai oleh siswa serta respon dan aktivitas siswa dalam proses pembelajaran. Untuk menganalisis tingkat keberasilan atau prosentasi keberasilan siswa selama proses pembelajaran dilakukan observasi terhadap sikap siswa dalam belajar dan pada akhir pembelajaran diadakan evaluasi berupa tes tertulis.
Analisis ini dilakukan dengan menggunakan data statistik sederhana, yaitu:

1. Untuk menilai ulangan tes formatif

Untuk mencari rata-rata nilai satu kelas peneliti melakukan penilaian dari hasil tes tertulis ini dengan cara melakukan penjumlahan semua nilai yang diperoleh oleh semua siswa dalam satu kelas kemudian dibagi dengan jumlah siswa dalam satu kelas.

\section{Untuk Ketuntasan Belajar}

Ada dua kategori ketuntasan belajar yaitu secara perorangan dan secara klasikal. Berdasar petunjuk pelaksanaan belajar mengajar kurikulum 1994 (Depdikbud, 1994), Yaitu seorang siswa telah tuntas belajar bila telah mencapai nilai 65 atau 75, dan kelas dikatakan tuntas belajar bila di kelas tersebut terdapat $85 \%$ yang telah mencapai daya serap lebih dari atau sama dengan $65 \%$. Cara menghitung ketuntasn belajar siswa adalah sebagai berikut :

a. Untuk menghitung kriteria ketuntasan belajar perorangan siswa digunakan rumus sebagai berikut:

Nilai $=$ jumlah skor yang diperoleh siswa $\mathrm{x} 10$

Dalam penelitian ini peneliti menganalisis data secara kuantitatif berupa skor yang diperoleh siswa dari tes tulis yang dikerjakannya. Butir soal yang digunakan berjumlah lima butir yang mewakili kopetensi yang harus dicapai oleh siswa dalam tindakan perbaikan. Dari kelima butir soal tersebut setiap butir soal yang dijawab dengan benar akan mendapat skor dua, apabila setiap butir soal dijawab tetapi tidak tepat jawabannya diberi skor 1 sedangkan butir soal yang tidak diberi jawaban tidak diberi skor. Apabila nilai yang diperoleh siswa diatas standar KKM yang telah ditentukan maka siswa dinyatakan tuntas dalam mencapai tujuan pembelajaran dan tindakan perbaikan yang dilakukan oleh peneliti dapat dikatakan berasil dan siklus bisa dihentikan, akan tetapi apabila nilai siswa di bawah standar KKM maka 
siswa dikatakan tidak tuntas dalam mencapai tujuan pembelajaran dan peneliti harus melakukan perencanaan lagi untuk melakukan tindakan perbaikan pembelajaran pada siklus berikutnya.

b. Untuk menghitung persentasi ketuntasan belajar siswa dalam satu kelas digunakan rumus sebagai berikut:

$$
\mathrm{P}=\frac{\sum \text { Siswa yang tuntas belajar }}{\%} \times 100
$$

3. Untuk menilai sikap siswa dalam proses pembelajaran

Pada kegiatan kelompok penilaian berdasarkan pada perilaku siswa selama pembelajaran berlangsung. Aspek yang dinilai pada saat observasi adalah aspek keberanian, kerjasama, dan ketepatan. Kriteria skor pada setiap aspek adalah sebagai berikut: 1) Aspek keberanian. Skor 4 jika siswa berani mengajukan dan menanggapi pendapat tanpa perintah guru. Skor 3 jika siswa berani mengajukan dan menanggapi pendapat setelah diperintah guru. Skor 2 jika siswa berani mengajukan dan menanggapi pendapat dengan dorongan teman. Skor 1 jika siswa pasif. 2) Aspek kerjasama. Skor 4 jika siswa melakukan kerjasama untuk memecahkan masalah yang dihadapi kelompok tanpa bimbingan guru. Skor 3 jika siswa melakukan kerjasama untuk memecahkan masalah yang dihadapi kelompok dengan bimbingan guru. Skor 2 jika siswa melakukan kerjasama untuk memecahkan masalah yang dihadapi kelompok dengan paksaan. Skor 1 jika siswa pasif. 3)Aspek ketepatan. Skor 4 jika siswa menjawab benar 4 pertanyaan. Skor 3 jika siswa menjawab 3 pertanyaan. Skor 2 jika siswa menjawab pertanyaan. Skor 1 jika siswa menjawab 1 pertanyaan. Nilai akhir yang diperoleh siswa dalam pengamatan dapat dihitung dengan cara sebagai berikut :
Skor Nilai $=\underline{\text { Jumlah Perolehan Skor }}$ X 100 Skor Maksimal

Apabila ketiga aspek diatas siwa belum bisa mencapai skor nilai $\mathrm{kkm} 70$ yang telah ditentukan maka siswa dikatakan kurang aktif mengikuti proses pembelajaran, untuk selanjutnya perlu diadakan lagi perencanaan perbaikan pembelajaran guna melaksanakan siklus berikutnya. Namun apabila siswa dapat mencapai nilai kkm 70 dari ketiga aspek yang telah ditentukan maka siswa dikatakan sudah aktif dalam proses pembelajaran dan siklus bisa dihentikan.

\section{HASIL DAN PEMBAHASAN}

\section{A. Deskripsi Hasil Penelitian Perbaikan Pembelajaran \\ 1) Pra Siklus \\ a. Perencanaan}

Menyusun rencana pelaksanaan pembelajaran sesuai mata pelajaran yang ditentukan Bahasa Indonesia beserta semua perangkat pembelajaran .

\section{b. Pelaksanaan}

Kegiatan Awal (5 menit)

- Salam pembuka

- Berdoa bersama

- Absensi

- Apersepsi

$\checkmark \quad$ Tepuk aku pasti bisa (Tepuk aku bisa, aku, pasti bisa, belajar, bahasa, Indonesia, pasti bisa, pasti bisa, pasti bisa, yes, yes, yes )

$\checkmark$ Tanya jawab cerpen yang pernah dibaca dan dilihat

- Menyampaikan tujuan pembelajaran yang dicapai

Kegiatan Inti ( 20 menit )

- Eksplorasi

$\checkmark$ Siswa bersama guru tanya jawab tentang unsur-cerita (tokoh, tema, latar, amanat) 
$\checkmark$ Siswa secara klasikal mendengarkan cerita keong emas yang dibacakan guru

- Elaborasi

$\checkmark$ Siswa dibagi menjadi empat kelompok

$\checkmark$ Siswa mendiskusikan lembar kegiatan kelompok

$\checkmark$ Siswa mempresentasikan hasil diskusi dengan bimbingan guru sedang kelompok lainnya menanggapinya

- Konfirmasi

$\checkmark$ Guru memberi penjelasan tentang hasil diskusi siswa dengan materi yang diajarkan

Kegiatan Akhir ( 10 menit )

- Dengan bimbingan guru siswa merangkum materi

- Siswa mengerjakan lembar individu

- Siswa dengan bimbingan guru mengoreksi lembar individu

- Guru memperjelas materi melalui tanya jawab

- Berdoa bersama

- Salam penutup

\section{c. Observasi}

Selama proses pembelajaran sebagai observer peneliti melakukan pengamatan dan mencatat semua kejadian selama pembelajaran dengan menggunakan lembar observasi dari teman sejawat, selain itu juga mencatat hasil pengamatan siswa selama pembelajaran dan mencatat hasil belajar siswa dari tes tertulis yang dikerjakan pada akhir pembelajaran. Sebelum perbaikan pembelajaran dilakukan, peneliti mengidentifikasi penyebab permasalahan ketuntasan hasil belajar siswa pada mata pelajaran Bahasa Indonesia dengan kemampuan dasar mengidentifikasi usur-unsur cerita pada siswa kelas V SDN Karangtengah 4 Kecamatan Ngawi Kabupaten Ngawi. Adapun data keaktifan siswa pada pra siklus dapat di lihat pada tabel 4.1 sedangkan data hasil evaluasi pra siklus dapat dilihat pada tabel 4.2 dan 4.3 serta grafik 4.1

Tabel 4.1

Hasil Pengamatan Keaktifan Siswa Pada Pra Siklus

\begin{tabular}{|c|l|c|c|}
\hline No. & \multicolumn{1}{|c|}{ Nama Siswa } & Skor & Keterangan \\
\hline 1 & abiyyu fadhilah t.a & 83 & Aktif \\
\hline 2 & adi kurniawan & 50 & Kurang Aktif \\
\hline 3 & amanda syifana a & 75 & Aktif \\
\hline 4 & adhinda widiya $\mathrm{r}$ & 66 & Kuramg Aktif \\
\hline 5 & ardy gusti pratama & 66 & Kurang Aktif \\
\hline 6 & amelia salsabila p.g & 83 & Aktif \\
\hline 7 & ananda dila kusuma & 83 & Aktif \\
\hline 8 & adhira maulina a & 75 & Aktif \\
\hline 9 & andika dwi setyawan & 75 & Aktif \\
\hline 10 & berta novita putri k.r & 66 & Kurang Aktif \\
\hline 11 & bagas wahyu j.p & 83 & Aktif \\
\hline 12 & krisna bayu p & 50 & Kurang Aktif \\
\hline 13 & marenza fernanda p.p & 50 & Kurang Aktif \\
\hline 14 & mohamad alan $\mathrm{f}$ & 66 & Kurang Aktif \\
\hline 15 & adidara rizki r & 83 & Aktif \\
\hline 16 & dwi retno agustina & 83 & Aktif \\
\hline 17 & adimas nugroho r.s & 83 & Aktif \\
\hline 18 & amalia rahmatin $\mathrm{n}$ & 66 & Kurang Aktif \\
\hline 19 & aditya rachmat k & 66 & Kurang Aktif \\
\hline 20 & anissa nurul i & 83 & Aktif \\
\hline 21 & ardo anan sudrajat & 83 & Aktif \\
\hline 22 & maharani chairatun & 66 & Kurang Aktif \\
\hline$\%$ Siswa Aktif & & $50 \%$ \\
\hline$\%$ Siswa tidak aktif & & $50 \%$ \\
\hline
\end{tabular}

Dari data pada tabel 4.1 di atas dapat diketahui bahwa keaktifan siswa kelas V SDN Karangtengah 4 hanya mencapai $50 \%$ dan yang kurang aktif mencapai 50\%. Oleh karena itu untuk meningkatkan keaktifan siswa maka diperlukan perbaikan pembelajaran .

Tabel 4.2

Data Nilai evaluasi Siswa Pra Siklus

\begin{tabular}{|c|c|c|c|}
\hline No. & Nama Siswa & $\begin{array}{c}\text { Nilai } \\
\text { Pra } \\
\text { Siklus }\end{array}$ & Keterangan \\
\hline 1 & abiyyu fadhilah t.a & 70 & Tuntas \\
\hline
\end{tabular}




\begin{tabular}{|c|l|c|c|}
\hline 2 & adi kurniawan & 30 & Belum Tuntas \\
\hline 3 & amanda syifana a & 70 & Tuntas \\
\hline 4 & adhinda widiya $\mathrm{r}$ & 60 & Belum Tuntas \\
\hline 5 & ardy gusti pratama & 60 & Belum Tuntas \\
\hline 6 & amelia salsabila p.g & 70 & Tuntas \\
\hline 7 & ananda dila kusuma & 70 & Tuntas \\
\hline 8 & adhira maulina a & 70 & Tuntas \\
\hline 9 & andika dwi setyawan & 70 & Tuntas \\
\hline 10 & berta novita putri k.r & 60 & Belum Tuntas \\
\hline 11 & bagas wahyu j.p & 70 & Tuntas \\
\hline 12 & krisna bayu p & 30 & Belum Tuntas \\
\hline 13 & marenza fernanda p.p & 40 & Belum Tuntas \\
\hline 14 & mohamad alan $\mathrm{f}$ & 60 & Belum Tuntas \\
\hline 15 & adidara rizki r & 60 & Belum Tuntas \\
\hline 16 & dwi retno agustina & 70 & Tuntas \\
\hline 17 & adimas nugroho r.s & 70 & Tuntas \\
\hline 18 & amalia rahmatin $\mathrm{n}$ & 60 & Belum Tuntas \\
\hline 19 & aditya rachmat $\mathrm{k}$ & 60 & Belum Tuntas \\
\hline 20 & anissa nurul i & 70 & Tuntas \\
\hline 21 & ardo anan sudrajat & 70 & Tuntas \\
\hline 22 & maharani chairatun $\mathrm{n}$ & 50 & Belum Tuntas \\
\hline & jumlah & 1340 & \\
\hline & rata-rata & 61 & \\
\hline & & & \\
\hline
\end{tabular}

Dari data pada tabel 4.2 dapat diketahui bahwa siswa yang mendapat nilai minimal 70 dinyatakan tuntas dan siswa yang mendapat nilai kurang dari 70 dinyatakan tindak tuntas. Selain itu dari data tabel 4.2 dapat diketahui juga bahwa siswa kelas $\mathrm{V}$ hanya mendapat nilai rata-rata 61 kurang dari standar yang ditentukan. Adapun data prosentasi ketuntasan hasil belajar pada pra siklus dapat kita lihat pada tabel 4.3 dan.

Tabel 4.3

Prosentasi Ketuntasan Hasil Belajar Pra Siklus

\begin{tabular}{|c|c|c|c|c|}
\hline No. & Nilai & $\begin{array}{c}\text { Jumlah } \\
\text { Siswa }\end{array}$ & $\begin{array}{c}\text { Prosentasi } \\
(\boldsymbol{\%})\end{array}$ & Keterangan \\
\hline 1. & $\geq 70$ & 11 & $50 \%$ & Tuntas \\
\hline 2. & $<70$ & 11 & $50 \%$ & $\begin{array}{c}\text { Belum } \\
\text { Tuntas }\end{array}$ \\
\hline
\end{tabular}

Apabila dilihat data dari tabel 4.2 dan 4.2 dapat dikatakan bahwa evaluasi hasil belajar siswa kelas V SDN Karangtengah 4 pada mata pelajaran Bahasa Indonesia khususnya kemampuan mendengarkan kurang memuaskan karena nilai rata-rata kelas hanya mencapai 61 sedangkan prosentasi ketuntasan hasil belajar hanya mencapai $50 \%$. Jadi masih ada $50 \%$ siswa atau 11 siswa yang nilainya masih $<70$. Sehingga perlu adanya perbaikan pembelajaran untuk meningkatkan hasil belajar siswa. Secara keseluruhan prosentasi nilai hasil belajar siswa kelas V SDN Karangtengah 4 pra siklus dapat dianalisis seperti pada tabel 4.4 dan grafik 4.2 di bawah ini.

Tabel 4.4

Analisis Data Hasil Tes Akhir Siswa Pra Siklus Siswa Kelas V

\begin{tabular}{|c|c|c|c|}
\hline No. & Nilai & Jumlah Siswa & Prosentasi (\%) \\
\hline 1. & 70 & 11 & $50 \%$ \\
\hline 2. & 60 & 7 & $31 \%$ \\
\hline 3. & 50 & 1 & $5 \%$ \\
\hline 4. & 40 & 1 & $5 \%$ \\
\hline 5. & 30 & 2 & $9 \%$ \\
\hline \multicolumn{2}{|c|}{ Jumlah } & 22 & $100 \%$ \\
\hline
\end{tabular}

Dari tabel 4.4 dapat dketahui bahwa belum ada siswa yang mendapat nilai di atas 70 yang merupakan standar dari $\mathrm{kkm}$ yang ditetapkan, hanya 11 siswa yang dapat mencapai nilai 70 dan yang lainnya di bawah nilai 70 . Melihat keadaan tersebut maka diperlukan perbaikan pembelajaran pada siswa kelas V SDN Karangtengah 4.

\section{d. Refleksi}

Berdasarkan pengamatan yang dilakukan ternyata ada beberapa kelemahan dan perlu diadakan refleksi bagaimana meningkatkan hasil belajar siswa kelas V SDN Karangtengah 4 pada kemampuan mendengarkan dengan memperbaiki metode ceramah dan media teks cerita dengan media lain yang lebih menarik bagi siswa.

\section{2) Siklus I}

\section{a. Perencanaan}

Yang dilakukan peneliti adalah mempersiapkan semua instrumen yang akan digunakan dalam pelaksanaan perbaikan pembelajaran. Adapun instrumen tersebut 
meliputi: RPP Perbaikan Siklus I, LKS, Lembar Observasi beserta rubrik penilaiannya, Soal Tes Tulis beserta kunci jawaban, Lembar penilaian beserta skor penilaian, menetapkan pelaksanaan siklus 1 pada tanggal 14 Maret 2015 dengan materi pokok unsur-unsur cerita dengan model cooperative learning dan media proyeksi LCD dalam proses pembelajaran

\section{b. Pelaksanaan Perbaikan}

Pelaksanaan perbaikan pembelajaran siklus I dilakukan pada tanggal 14 Maret 2015 di kelas V SDN Karangtengah 4 Kecamatan Ngawi Tahun Pelajaran 2014/2015. Pelaksanaan perbaikan pembelajaran siklus 1 mengacu pada RPP Perbaikan Siklus I yang telah disiapkan pada tahap perencanaan, dengan urutan pembelajaran sebagai berikut :

$>$ Kegiatan Awal ( 5 menit )

- Salam pembuka

- Berdoa bersama

- Absensi

- Apersepsi

$\checkmark$ Tepuk aku pasti bisa (Tepuk aku bisa, aku, pasti bisa, belajar, bahasa, Indonesia, pasti bisa, pasti bisa, pasti bisa, yes, yes, yes )

$\checkmark \quad$ Tanya jawab cerpen yang pernah dibaca dan dilihat

- Menyampaikan tujuan pembelajaran yang dicapai

$>$ Kegiatan Inti (20 menit )

- Eksplorasi

$\checkmark$ Siswa bersama guru tanya jawab tentang unsur-cerita (tokoh, tema, latar, amanat)

$\checkmark \quad$ Siswa secara klasikal melihat film keong emas pada proyektor

- Elaborasi

$\checkmark$ Siswa dibagi menjadi empat kelompok

$\checkmark$ Siswa mendiskusikan lembar kegiatan kelompok $\checkmark$ Siswa mempresentasikan hasil diskusi dengan bimbingan guru sedang kelompok lainnya menanggapinya

- Konfirmasi

$\checkmark$ Guru memberi penjelasan tentang hasil diskusi siswa dengan materi yang diajarkan

Kegiatan Akhir ( 10 menit )

- Dengan bimbingan guru siswa merangkum materi

- Siswa mengerjakan lembar individu

- Siswa dengan bimbingan guru mengoreksi lembar individu

- Guru memperjelas materi melalui tanya jawab

- Berdoa bersama

- Salam penutup

\section{c. Observasi}

Guru atau peneliti melaksanakan penelitian dan mencatat semua data yang diperlukan dalam perbaikan di lembar penilaian yang telah disiapkan sebelumnya bersamaan pada saat prose pembelajaran sedang berlangsung. Adapun datadata yang diperoleh pada siklus I adalah sebagai berikut. Dari hasil pengamatan keaktifan siswa diperoleh hasil pengamatan seperti pada tabel di bawah ini.

Tabel 4.5

Hasil Pengamatan Keaktifan Siswa Siklus 1

\begin{tabular}{|c|l|c|c|}
\hline No. & \multicolumn{1}{|c|}{ Nama Siswa } & $\begin{array}{c}\text { Skor } \\
\text { Keaktifan }\end{array}$ & Keterangan \\
\hline 1 & danang budi $p$ & $\mathbf{8 3}$ & Aktif \\
\hline 2 & abiyyu fadhilah t.a & 75 & Aktif \\
\hline 3 & adi kurniawan & 75 & Aktif \\
\hline 4 & amanda syifana a & 66 & Kurang Aktif \\
\hline 5 & adhinda widiya $\mathrm{r}$ & 66 & Kurang Aktif \\
\hline 6 & ardy gusti pratama & 83 & Aktif \\
\hline 7 & $\begin{array}{l}\text { amelia salsabila } \\
\text { p.g }\end{array}$ & 83 & Aktif \\
\hline 8 & $\begin{array}{l}\text { ananda dila } \\
\text { kusuma }\end{array}$ & 75 & Aktif \\
\hline 9 & adhira maulina a & 75 & Aktif \\
\hline
\end{tabular}




\begin{tabular}{|c|c|c|c|}
\hline 10 & $\begin{array}{l}\text { andika dwi } \\
\text { setyawan }\end{array}$ & 66 & Kurang Aktif \\
\hline 11 & $\begin{array}{l}\text { berta novita putri } \\
\text { k.r }\end{array}$ & 83 & Aktif \\
\hline 12 & bagas wahyu j.p & 66 & Kurang Aktif \\
\hline 13 & krisna bayu p & 75 & Aktif \\
\hline 14 & $\begin{array}{l}\text { marenza fernanda } \\
\text { p.p }\end{array}$ & 66 & Kurang Aktif \\
\hline 15 & mohamad alan f & 83 & Aktif \\
\hline 16 & adidara rizki r & 83 & Aktif \\
\hline 17 & dwi retno agustina & 83 & Aktif \\
\hline 18 & adimas nugroho r.s & 75 & Aktif \\
\hline 19 & amalia rahmatin $\mathrm{n}$ & 66 & Kurang Aktif \\
\hline 20 & aditya rachmat k & 75 & Aktif \\
\hline 21 & anissa nurul i & 83 & Aktif \\
\hline 22 & ardo anan sudrajat & 83 & Aktif \\
\hline & \% Siswa Aktif & & $72 \%$ \\
\hline \multicolumn{2}{|c|}{ \% Siswa tidak aktif } & & $27 \%$ \\
\hline
\end{tabular}

Berdasar data pada tabel 4.5 dapat diketahui bahwa keaktifan siswa kelas $\mathrm{V}$ sudah mengalami peningkatan menjadi $72 \%$. Karena masih ada $27 \%$ siswa yang kurang aktif maka perlu diadakan perbaikan kembali pada siklus ke dua. Adapun hasil belajar siswa dapat dilihat pada tabel 4.6 di bawah ini.

Tabel 4.6

Data Nilai evaluasi Siswa Siklus 1

\begin{tabular}{|c|l|c|c|}
\hline No. & \multicolumn{1}{|c|}{ Nama Siswa } & $\begin{array}{c}\text { Nilai } \\
\text { Pra } \\
\text { Siklus }\end{array}$ & Keterangan \\
\hline 1 & danang budi p & 90 & Tuntas \\
\hline 2 & abiyyu fadhilah t.a & 50 & Belum Tuntas \\
\hline 3 & adi kurniawan & 90 & Tuntas \\
\hline 4 & amanda syifana a & 80 & Tuntas \\
\hline 5 & adhinda widiya r & 60 & Belum Tuntas \\
\hline 6 & ardy gusti pratama & 90 & Tuntas \\
\hline 7 & amelia salsabila p.g & 90 & Tuntas \\
\hline 8 & ananda dila kusuma & 90 & Tuntas \\
\hline 9 & adhira maulina a & 90 & Tuntas \\
\hline 10 & andika dwi setyawan & 60 & Belum Tuntas \\
\hline 11 & berta novita putri k.r & 90 & Tuntas \\
\hline 12 & bagas wahyu j.p & 50 & Belum Tuntas \\
\hline 13 & krisna bayu p & 60 & Belum Tuntas \\
\hline 14 & marenza fernanda p.p & 80 & Tuntas \\
\hline 15 & mohamad alan f & 80 & Tuntas \\
\hline 16 & adidara rizki r & 90 & Tuntas \\
\hline 17 & dwi retno agustina & 90 & Tuntas \\
\hline
\end{tabular}

\begin{tabular}{|c|l|c|c|}
\hline 18 & adimas nugroho r.s & 60 & Belum Tuntas \\
\hline 19 & amalia rahmatin $\mathrm{n}$ & 80 & Tuntas \\
\hline 20 & aditya rachmat $\mathrm{k}$ & 90 & Tuntas \\
\hline 21 & anissa nurul i & 90 & Tuntas \\
\hline 22 & ardo anan sudrajat & 70 & Tuntas \\
\hline \multicolumn{2}{|c|}{ Jumlah } & $\mathbf{1 6 5 0}$ & \\
\hline \multicolumn{2}{|c|}{ Rata-rata } & $\mathbf{7 5}$ & \\
\hline
\end{tabular}

Berdasarkan Tabel 4.7 dapat dilihat bahwa ketuntasan hasill belajar siswa kelas $\mathrm{V}$ mengalami peningkatan menjadi $73 \%$ setelah menerapkan model cooperative learning dan media proyeksi LCD sedang siswa yang belum tuntas berkurang menjadi $27 \%$. Namun demikia agar hasil belajar siswa lebih meningkat mak diperlkan perbaikan pembelajaran kembali. Secara keseluruhan prosentasi hasil belajar siklus 1 pada siswa kelas V Karangtengah 4 dapat dianalisi seperti pada tabel 4.8 .

Tabel 4.8 Analisis Data Hasil Tes Akhir Siswa Siklus 1 Siswa Kelas V

\begin{tabular}{|c|c|c|c|}
\hline No. & Nilai & $\begin{array}{c}\text { Jumlah } \\
\text { Siswa }\end{array}$ & $\begin{array}{c}\text { Prosentase } \\
(\%)\end{array}$ \\
\hline 1. & 90 & 11 & $50 \%$ \\
\hline 2. & 80 & 4 & $18 \%$ \\
\hline 3. & 70 & 1 & $4 \%$ \\
\hline 4. & 60 & 4 & $18 \%$ \\
\hline 5. & 50 & 2 & $10 \%$ \\
\hline \multicolumn{2}{|c|}{ Jumlah } & 22 & $100 \%$ \\
\hline
\end{tabular}

Dari tabel 4.8 dapat kita simpulkan bahwa hasil belajar siswa yang mendapat nilai 90 mencapai $50 \%$. Sedangkan siswa yang mendapatkan nilai terbawah yaitu 50 hanya $10 \%$. Agar siswa kelas V SDN Karangtengah 4 mendapatkan hasil belajar lebih maksimal lagi, maka perbaikan pembelajaran masih diperlukan lagi.

\section{d. Refleksi}

Berdasarkan pelaksanaan perbaikan dengan menggunakan model belajar cooperative learning dan media proeksi LCD pada siklua 1 
dan observasi yang dilakukan maka diperoleh data sebagai berikut:

1. Keaktifan siswa selama proses pembelajaran mengalamami peningkatan dari $50 \%$ menjadi $72 \%$

2. Hasil tes akhir pelaksanaan perbaikan mengalami peningkatan pula yang sebelumnya siswa yang tuntas belajar hanya 11 siswa dengan prosentasi $50 \%$ menjadi 16 siswa yang bisa tuntas belajar dengan prosentasi $73 \%$.

Pelaksanaan perbaikan siklus 1 telah dapat meningkatkan hasil belajar siswa kelas V SDN Karangtengah 4 dan keaktifan siswa selama proses pembelajaran, agar hasil belajar dan keaktifan siswa lebih meningkat semua maka perlu diadakan pelaksanaan perbaikan pembelajaran pada siklus.

\section{3) Siklus 2}

\section{a. Perencanaan Perbaikan}

Perencanaan tindakkan pada siklus dua disusun meliputi: 1) Membuat RPP perbaikan, 2) Menentukan tujuan perbaikan dengan tetap mengunakan model coopertive learning dengan media proyeksi learning hanya ditambah meningkatkan keterampilan bertanya secara lisan agar siswa lebih mudah memahami tugas yang harus mereka lakukan, 3) menyiapkan lembar kerja siswa, 4) menyiapkan instrumen tes tertulis, 5) menyiapkan lembar pengamatan dan lembar evaluasi, 5) menentukan tanggal pelaksanaan perbaikan pembelajaran pada tanggal 24 Maret 2015.

\section{b. Pelaksanaan Perbaikan}

Pelaksanaan perbaikan pada siklus 2 dilaksanakan pada tanggan 24 Maret 2015 di kelas V SDN Karangtengah 4 Kecamatan Ngawi. Pelaksanaan perbaikan pembelajaran pada siklus 2 ini mengacu pada RPP Perbaikan siklus 2, dengan urutan pembelajaran sebagai berikut:

$>$ Kegiatan Awal ( 5 menit )

- Salam pembuka

- Berdoa bersama
- Absensi

- Apersepsi

$\checkmark$ Tepuk aku pasti bisa (Tepuk aku bisa, aku, pasti bisa, belajar, bahasa, Indonesia, pasti bisa, pasti bisa, pasti bisa, yes, yes, yes)

$\checkmark$ Tanya jawab cerpen yang pernah dibaca dan dilihat

- Menyampaikan tujuan pembelajaran yang dicapai

Kegiatan Inti (20 menit )

- Eksplorasi

$\checkmark$ Siswa bersama guru tanya jawab tentang unsur-cerita (tokoh, tema, latar, amanat)

$\checkmark$ Siswa secara klasikal melihat film harta temuaan pada proyektor

- Elaborasi

$\checkmark$ Siswa dibagi menjadi empat kelompok

$\checkmark$ Siswa mendiskusikan lembar kegiatan kelompok

$\checkmark$ Siswa mempresentasikan hasil diskusi dengan bimbingan guru sedang kelompok lainnya menanggapinya

- Konfirmasi

$\checkmark$ Guru memberi penjelasan tentang hasil diskusi siswa dengan materi yang diajarkan

Kegiatan Akhir ( 10 menit )

- Dengan bimbingan guru siswa merangkum materi

- Siswa mengerjakan lembar individu

- Siswa dengan bimbingan guru mengoreksi lembar individu

- Guru memperjelas materi melalui tanya jawab

- Berdoa bersama

- Salam penutup

\section{c. Observasi}

Kegiatan observasi dilaksanakan bersamaan dengan tahap pelaksanaan. Dengan cara mencatat data-data yang diamati ke dalam 
instrumen yang telah direncanakan. Adapun data-data yang dapat ditemukan adalah sebagai berikut.

Tabel 4.9

Hasil Pengamatan Keaktifan Siswa Siklus 2

\begin{tabular}{|c|l|c|c|}
\hline No. & \multicolumn{1}{|c|}{ Nama Siswa } & Skor & Ket \\
\hline 1 & danang budi $\mathrm{p}$ & 92 & Aktif \\
\hline 2 & aziz putra $\mathrm{k}$ & 75 & Aktif \\
\hline 3 & erna tri $\mathrm{f}$ & 92 & Aktif \\
\hline 4 & kieki fitriani s & 83 & Aktif \\
\hline 5 & malikul khahfi & 83 & Aktif \\
\hline 6 & alfina mei $\mathrm{m}$ & 83 & Aktif \\
\hline 7 & anatasaya $\mathrm{r}$ & 83 & Aktif \\
\hline 8 & azzahra ristiani & 75 & Aktif \\
\hline 9 & bagas aldi $\mathrm{p}$ & 83 & Aktif \\
\hline 10 & dintia ayu $\mathrm{g}$ & 75 & Aktif \\
\hline 11 & fajar wildani & 83 & Aktif \\
\hline 12 & ixzan $\mathrm{f}$ & 66 & Tidak Aktif \\
\hline 13 & kevin andra s & 75 & Aktif \\
\hline 14 & mohammad y & 66 & Tidak Aktif \\
\hline 15 & mohammad roi s & 83 & Aktif \\
\hline 16 & nur avika $\mathrm{r}$ & 83 & Aktif \\
\hline 17 & revaldo h.h & 92 & Aktif \\
\hline 18 & velia cahyani $\mathrm{f}$ & 75 & Aktif \\
\hline 19 & wahyu sheva s $\mathrm{p}$ & 75 & Aktif \\
\hline 20 & berliana indah s & 83 & Aktif \\
\hline 21 & tribrata pudjiono & 83 & Aktif \\
\hline 22 & vina aprilia & 66 & Tidak Aktif \\
\hline & \% siswa aktif & & $\mathbf{8 6} \%$ \\
\hline & $\%$ siswa tidak aktif & & $\mathbf{1 4} \%$ \\
\hline & & & \\
\hline & & & \\
\hline & & & \\
\hline
\end{tabular}

Berdasarkan tabel 4.9 keaktifan siswa mengalami peningkatan yang cukup baik yang sebelumnya hanya mencapai $72 \%$ menjadi 86 $\%$.

Tabel 4.10

Data Nilai evaluasi Siswa Siklus 2

\begin{tabular}{|c|l|c|c|}
\hline No. & \multicolumn{1}{|c|}{ Nama Siswa } & $\begin{array}{c}\text { Nilai Pra } \\
\text { Siklus }\end{array}$ & Ket \\
\hline 1 & danang budi $\mathrm{p}$ & 90 & Tuntas \\
\hline 2 & aziz putra $\mathrm{k}$ & 90 & Tuntas \\
\hline 3 & erna tri $\mathrm{f}$ & 90 & Tuntas \\
\hline 4 & kieki fitriani $\mathrm{s}$ & 90 & Tuntas \\
\hline 5 & malikul khahfi & 80 & Tuntas \\
\hline 6 & alfina mei $\mathrm{m}$ & 90 & Tuntas \\
\hline 7 & anatasaya $\mathrm{r}$ & 100 & Tuntas \\
\hline 8 & azzahra ristiani & 80 & Tuntas \\
\hline 9 & bagas aldi $\mathrm{p}$ & 90 & Tuntas \\
\hline 10 & dintia ayu $\mathrm{g}$ & 90 & Tunta \\
\hline
\end{tabular}

\begin{tabular}{|c|c|c|c|}
\hline 11 & fajar wildani & 90 & Tuntas \\
\hline 12 & ixzan $\mathrm{f}$ & 100 & Tuntas \\
\hline 13 & kevin andra $\mathrm{s}$ & 90 & Tuntas \\
\hline 14 & mohammad y & 90 & Tuntas \\
\hline 15 & mohammad roi s & 90 & Tuntas \\
\hline 16 & nur avika $\mathrm{r}$ & 90 & Tuntas \\
\hline 17 & revaldo h.h & 90 & Tuntas \\
\hline 18 & velia cahyani f & 90 & Tuntas \\
\hline 19 & wahyu sheva $\mathrm{sp}$ & 90 & Tuntas \\
\hline 20 & berliana indah s & 90 & Tuntas \\
\hline 21 & tribrata pudjiono & 90 & Tuntas \\
\hline 22 & vina aprilia & 90 & Tuntas \\
\hline \multicolumn{2}{|r|}{ jumlah } & 1980 & \\
\hline \multicolumn{2}{|r|}{ rata-rata } & 90 & \\
\hline
\end{tabular}

Dari data di atas dapat diketahui rata-rata nilai siswa kelas $\mathrm{V}$ mengalami perkembangan menjadi 90. Selain itu dapat dilihat nilai hasil belajar semua siswa sudah di atas KKM yang ditentukan yaitu 70 .

Tabel 4.11

Prosentase Ketuntasan Hasil Belajar siklus 2

\begin{tabular}{|c|c|c|c|c|}
\hline No. & Nilai & $\begin{array}{c}\text { Jumlah } \\
\text { Siswa }\end{array}$ & $\begin{array}{c}\text { Prosentasi } \\
(\%)\end{array}$ & Ket \\
\hline 1. & $\geq 70$ & 22 & $100 \%$ & Tuntas \\
\hline 2. & $<70$ & 0 & $0 \%$ & $\begin{array}{c}\text { Belum } \\
\text { Tuntas }\end{array}$ \\
\hline
\end{tabular}

Dari tabel 4.11 menunjukkan bahwa hasil belajar semua siswa kelas V sudah diatas KKM sebanyak $100 \%$. Dan tidak satupun yang mendapatkan nilai dibawah KKM.

Tabel 4.12

Analisis Data Hasil Tes Akhir Siswa Siklus 2 Siswa Kelas V

\begin{tabular}{|c|c|c|c|}
\hline No. & Nilai & Jumlah Siswa & Prosentase (\%) \\
\hline 1. & 100 & 2 & $9 \%$ \\
\hline 2. & 90 & 18 & $82 \%$ \\
\hline 3. & 80 & 2 & $9 \%$ \\
\hline \multicolumn{2}{|c|}{ Jumlah } & 22 & $100 \%$ \\
\hline
\end{tabular}

\section{d.Refleksi}

Berdasarkan hasil pengamatan pada pelaksanaan perbaikan pembelajaran pada siklus ke 2 diperoleh data sebagai berikut : 1) Nilai Rata-rata siswa kelas V mengalami peningkatan 
kembali yang pada siklus 1 hanya mendapat 75 sekarang pada siklus dua memperoleh rata-rata 90. 2) Hasil belajar siswa kelas V pada siklus ke dua ini juga meningkat yang sebelumnya siswa yang belum mencapai KKM ada 6 siswa maka pada siklus ke dua ini semua siswa $100 \%$ mendapat nilai di atas KKM (Tuntas semua), 3) Dari hasil observasi terhadap sikap siswa selama proses pembelajaran pada siklus ke dua $86 \%$ siswa sudah dapat aktif mengikuti proses pembelajaran. Pada Perbaikan pembelajaran siklus dua ini sudah dapat meningkatkan hasil belajar dan keaktifan siswa kelas V SDN Karangtengah 4 di dalam mempelajari mata pelajaran Bahasa Indonesia pada kemampuan mendengar kompetensi dasar mengidentifikasi unsur cerita.

\section{B. Pembahasan Hasil Penelitian Perbaikan Pembelajaran}

\section{Motivasi, Minat dan Keaktifan Siswa}

Penerapan model cooperative learning dan media proyeksi LCD dapat meningkatkan motivasi siswa kelas V SDN Karangtengah 4 Kecamatan Ngawi. Hal ini dapat dilihat dari meningkatnya keaktifan siswa pada saat mengikuti proses pembelajaran dari pra siklus (yang masih menggunakan metode ceramah dan media teks) mendapat $50 \%$ (11), kemudian siklus $172 \%$ (16) kemudian meningkat lagi pada siklus ke 2 menjadi $86 \%$. (19). Penggunaan model Cooperative Learning dan media proyeksi LCD membuat siswa lebih tertarik dalam belajar sehingga memotivasi siswa untuk senang dalam mempelajari mata pelajaran Bahasa Indonesia pada kemampuan mendengarkan.

\section{Peningkatan Hasil Belajar}

Penerapan Model Cooperative Learning juga mempengaruhi peningkatan hasil belajar siswa kelas V SDN Karangtengah 4 Kecamatan Ngawi. Hal ini dapat terlihat dari hasil nilai ratarata siswa yang meningkat dari pembelajaran pra siklus mendapatkan nilai rata-rata 60,9 pada perbaikan pembelajaran siklus 1 mendapat nilai rata-rata 75 kemudian pada perbaikan pembelajaran siklus 2 mendapat nilai rata-rata 90. Meningkatnya nilai rata-rata siswa kelas V disebabkan adanya motivasi siswa yang senang mengikuti proses pembelajaran karena guru di dalam pembelajarannya menggunakan model Cooperatif Learning dan media proyeksi LCD yang membuat siswa tertarik untuk mempelajari mata pelajaran Bahasa Indonesia khususnya pada kemampuan mendengarkan dengan kompetensi dasar mengidentifikasi unsur-unsur cerita. Hal ini sesuai dengan gagasan utama pemilihan model belajar cooperative learning yang sesuai dengan karakteristik sosial anak usia sekolah dasar yang mulai senang bekerja sama dan berkelompok bersama temannya. Sedangkan media proyeksi LCD adalah salah satu media pembelajaran modern yang dapat menyampaikan materi yang bisa ditangkap oleh siswa secara visual dan auditori yang akan lebih mempercepat daya serap dan pemahaman siswa pada saat belajar daripada dengan media yang hanya bisa ditangkap oleh indera penglihatan atau pendengaran saja.

\section{Ketuntasan Belajar Siswa}

Ktriteria Ketuntasan Minimal (KKM) yang sudah ditentukan yaitu 70 ternyata sudah dapat dicapai pada siklus 1 dan semakin maksimal tercapai pada siklus yang kedua . Pada awalnya pra siklus ketuntasan hasil belajar siswa kelas V SDN Karangtengah 4 mencapai $50 \%$ pada siklus 1 mencapai $73 \%$ dan pada siklus 2 mencapai $100 \%$. Adapun kenaikan ketuntasa hasil belajar siswa kelas V SDN Karangtengah 4 dapat dilihat pada grafik 4.7 


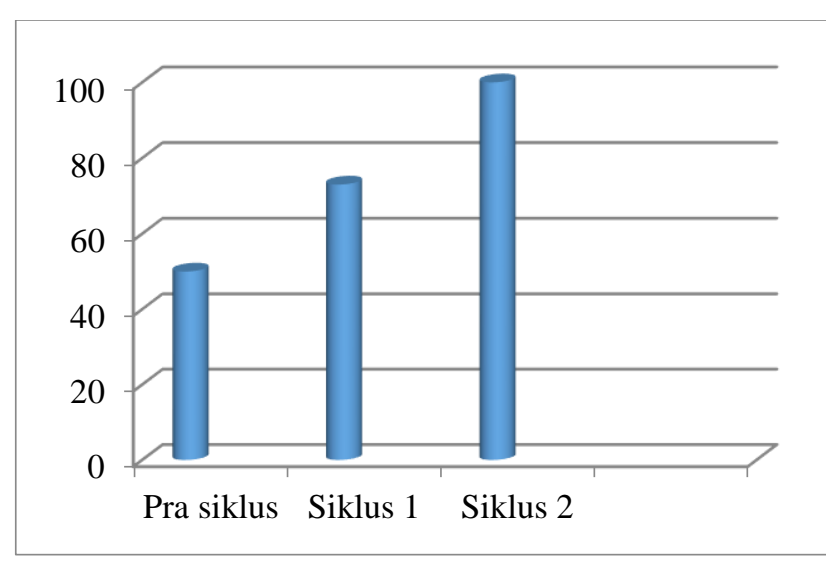

Prosentase Ketuntasan Belajar Persiklus

Berdasarkan hasil pada grafik 4.7 dapat dikatakan bahwa model cooperative learning dan media proyeksi LCD dapat meningkatkan hasil belajar siswa kelas V SDN Karangtengah 4 Kecamatan Ngawi pada kemampuan mendengarkan pada mata pelajaran Bahasa Indonesia baik secara individu atau kelompok.

\section{KESIMPULAN}

Berdasarkan dari analisis hasil pelaksanaan pembelajaran pra siklus yang masih menggunakan metode ceramah dan media buku teks dan berdasarkan hasil analisis perbaikan pembelajaran yang telah dilakukan pada siklus 1 dan siklus 2 yang menggunakan model cooperative learning melalui media proyeksi LCD pada pembelajaran keterampilan mendengarkan pada kelas V SDN Karangtengah 4 Kecamatan Ngawi terbukti dapat meningkatkan hasil belajar siswa kelas $\mathrm{V}$ yang sebelumnya pada pra siklus siswa yang mendapat nilai di atas KKM hanya mencapai 50 \% (11 siswa) kemudian meningkat pada siklus 1 yaitu $73 \%$ (16 siswa) lalu meningkat lagi pada siklus 2 menjadi $100 \%$ (22 siswa).

\section{SARAN}

Berdasarkan dari kesimpulan di atas maka penerapan model belajar cooperatif learning dengan media proyeksi LCD dapat digunakan sebagai:
1. Wawasan bagi mahasiswa sebagai calon guru sekolah dasar dalam menentukan model dan media pembelajaran pada saat mengajar.

2. Salah satu model dan media alternatif bagi guru dalam merencanakan pelaksanaan pembelajaran khususnya mata pelajaran Bahasa Indonesia pada keterampilan mendengarkan di kelas V sekolah dasar.

3. Bahan referensi bagi semua pihak dalam menentukan model belajar dan media beajar yang akan digunakan dalam pembelajaran khususnya mata pelajaran Bahasa Indonesia.

\section{DAFTAR PUSTAKA}

Anitah W, DKK, S. (2010). Strategi Pembelajaran di SD. Jakarta: Universitas Terbuka.

Sumantri, M. (2014). Perkembangan Bahasa:Fungsi Bahasa. Dalam Siti Nurhayati (Ed.1), Perkembangan Peserta Didik (hal. 2.23-2.24). Tangerang Selatan: Universitas Terbuka.

Suryanto, dkk, A. (2012). Mengumpulkan dan Mengolah Informasi Hasil Belajar: Tes dan Non Tes. Dalam Syamsir (Ed.1), Evaluasi Pembelajaran di SD. Tangerang Selatan: Universitas Terbuka.

Solchan T.W.,dkk. (2011). Pendidikan Bahasa Indonesia di SD.Jakarta: Universitas Terbuka.

Sudrajat, A. (2008). Pengertian Pendekatan, Strategi, Metode, Teknik, Taktik dan Model Pembelajaran. Diunduh tanggal 26 Maret 2015 dari https://akhmadsudrajat.wordpress.com/ Wikipedia Bahasa Indonesia. (2014). Proyektor LCD. Diunduh tanggal 2 April 2015 dari http://id.wikipedia.org/wiki/Proyektor_L CD

Wardani, dkk, IG.A.K. (2009). Perspektif Pendidikan SD. Jakarta:Universitas Terbuka. 
Wardhani, I dan Wihardhani, K. (2013).

Penelitian Tindakan Kelas. Tangerang

Selatan: Universitas Terbuka. 